\title{
Attention and Working Memory Training: The Effect of Reha Com Software on Cognitive Skills in a Non- Clinical Sample
}

\author{
Miruna C Barbu ${ }^{1 *}$, Róisín M Furlong ${ }^{1}$, Blanca Poveda ${ }^{2}$ and Jen Scotland ${ }^{2}$ \\ ${ }^{1}$ University of Edinburgh, Edinburgh, UK \\ ${ }^{2}$ NHS Lothian, Clinical Neuropsychology Department, Astley Ainslie Hospital, Edinburgh, UK
}

Submission: May 5, 2017; Published: June 27, 2017

*Corresponding author: Miruna C Barbu, Department of Psychiatry, University of Edinburgh, UK, Tel: +44 7821136 703;

Email: mirunabarbu94@gmail.com

\begin{abstract}
Objective: The present study investigated the efficacy of RehaCom, a computerized cognitive training program, in improving memory and attention functions in the healthy, adult brain in comparison to playing a simple game (Solitaire).

Method: 57 healthy participants completed either 9 sessions of attention and memory training within RehaCom or a simple game (Solitaire), for 30 minutes, 3 times a week for 3 weeks. Five pre- and post-training neuropsychological assessments were used to measure attention and memory, and level of anxiety and depression.

Results: Results showed no significant differences between the experimental group and the active control group. Both groups showed a non-significant improvement in attention and memory over time as shown on scores in post-training assessments. This result indicated that, although both groups improved in terms of memory and attention function, RehaCom did not play a role in this improvement. However, participants in the experimental group showed a steady improvement over training sessions.
\end{abstract}

Conclusion: The study presents the novelty of testing RehaCom in a healthy population and the finding that it does not greatly improve memory and attention functions in a selection of healthy individuals. Further research is needed in order to assert its efficacy in improving cognitive functions across both healthy and patient populations.

Keywords: Attention; Memory; Reha Com; Cognitive function

Abbreviations: WM: Working memory; WMC: Working Memory Capacity; RBANS: Repeatable Battery for the Assessment of Neuropsychological Status

\section{Introduction}

Working memory (WM) and attention are important cognitive processes which are implicated in a range of everyday activities, such as planning, problem-solving, learning, driving and engaging in social interactions [1,2] Wood (1990). While attention and WM are often studied individually, there is evidence to suggest that the processes are closely linked and facilitate the successful performance of common cognitive tasks $[3,4]$. Higher WM capacity is consistently associated with greater selective attention ability [5-8].

This relationship can be considered reciprocal, with greater attentional abilities allowing information to be filtered more effectively for maintenance and manipulation by the WM system
Baddeley, Hitch [9]. Those with greater WM abilities tend to perform better on a varied range of tasks including emotion regulation Schmeichel BJ [10], logic and problem solving [11,12], focus [13], and multi-tasking [14-16]. Therefore, improving one's attention and memory is potentially highly beneficial, as these resources are used in numerous areas, including professional, social and everyday tasks, and are crucial to an efficient and normal functioning [17].

\section{Brain Training}

A significant body of research now supports the idea that prolonged activation of cognitive processes can lead to lasting improvements in WM and attention [17-20]. By having people 
repeatedly perform tasks which require the use of the WM system, for example, it may be Possible to improve functioning on other untrained tasks Jaeggi [21].

Improvements in WM and attention may be achieved through the use of neuroplasticity, the brain's potential to readapt by forming novel neural pathways, aiding in improving and re-structuring levels of cognitive functions Dye [22]. Studies have shown that neuroplasticity alters neural pathways in order to form structural changes in the brain. For example, Draganski et al. [23] aimed to investigate the process of neuroplasticity in individuals who learned to juggle. They found novel structural changes in areas responsible for processing and storing visual motion. This suggests that training could aid neuroplasticity, which improves functions in the brain associated with certain stimuli. Therefore, as neuroplasticity permits a restructuration of neuronal pathways in order to optimize cognitive functions, cognitive training may encourage this development in order to improve an individual's cognition.

Much research has focused on training WM, in particular. One of the main proponents of WM training, Klingberg [24] proposes some general criteria that need to be met in order for training to have a positive effect. Firstly, the training should involve activation of the particular cognitive system, rather than the teaching of strategies.

For example, memory strategies and rehearsal techniques provide a means of increasing success on a specific task; however this approach does not change the underlying Working Memory Capacity (WMC) and therefore cannot generalize to other WM tasks. Training should also be adaptive, meaning that as a person improves at a given task, the level of difficulty increases accordingly [25]. Klingberg [24] states that in order for training to be effective, a person must always be pushed to the edge of their capabilities, but not beyond. From a neural perspective, the stress caused by an imbalance between available and required resources is what promotes cortical plasticity in both healthy and damaged brains [26,27].

Many studies have produced results that support the idea that cognitive training can improve memory and attention performance on related tasks (near transfer). Heinzel et al [28] used an n-back training paradigm, in which participants were asked to respond when a presented stimulus matched a previous stimulus presented a given (n) number of trials before. After completing 12 training sessions of 45 minutes each, significant improvements were noted on the trained task. Further, there was a significant improvement in performance on another verbal WM task - Forward Digit Span, as well as on measures of executive functioning and delayed recall. No such effect was seen in the control group, though this study utilized a passive control group which is a major limitation of this study.

Smith et al. [29] investigated the effects of a computerised cognitive training program on memory and attention in 487 healthy older adults. Half of the participants received plasticitybased cognitive training, while the control group viewed educational DVDs, for 40 hours over 8 weeks. Following the intervention, the training group had improved at the training tasks as measured by a significant increase in the speed and accuracy of information processing. Further, there was a marked improvement in attentional and memory abilities in the experimental group as compared to the control group, measured using subtests of the Repeatable Battery for the Assessment of Neuropsychological Status (RBANS). Those in the training group also self-reported much greater feelings of improvement in their cognitive functioning than those in the control group.

Brehmer [30] used an active control group in their study, which investigated WM training using the commercially available Cogmed QM training software Klingberg [31]. Participants undertook adaptive training sessions for 5 weeks, while controls used the same software at a non-adaptive, low level. Taskspecific gains were seen, as well as improvement on related but untrained measures of verbal, visual and spatial WM. The training also resulted in improved performance on a measure of sustained attention, with all gains maintained after an interval of 3 months.

Transfer of training to outcomes that less closely resemble the training tasks is known as far transfer. An example of this is academic achievement, as used by Söderqvist [32] to discern the effects of WM training on children's school performance. Quite often studies include a measure of intelligence or general cognitive function in order to discern whether the improvements gained through training that are observed on conceptually similar tasks, generalise to overall functioning [33,34]. Jaeggi et al. [21] found a significant increase in scores on standardized measures of fluid intelligence after a computerised WM training intervention. More general measures have also been used Mahncke et al. [35] found that after a period of WM training, participants performed significantly better on a general measure of neuropsychological functioning that encompassed functions such as memory, attention and processing speed. These effects remained in the domain of memory at a three-month followup. If the aim of training research is to improve an individual's overall quality of life, it is important to include a measure of far transfer as this provides an indication of the ecological validity of cognitive training outcomes.

Regarding dosage, different training schedules have been used across studies Penner et al. [36]. Commercial products usually provide recommended dosages, e.g. Cogmed - 40 minutes per day for 25 days Klingberg et al. [18]. However, these schedules are often not practical given the time and resources needed, and potential fatigue experienced by the participant Söderqvist [32]. Brief sessions of brain training have been found to have significant positive effects in several studies [37-39]. Zinke et al. [39] undertook WM training with a sample of older people during 9 sessions, of 30 minutes each, over 3 weeks. The 
results showed that training had a transfer effect to verbal WM and that these gains were still present 9 months later. This type of efficacy was also noted by Loosli et al. [38]. A schedule of 12-minute training sessions, 5 times per week for 2 weeks was used with a sample of schoolchildren. After this relatively short intervention, children improved significantly on the training task and showed superior reading ability compared to a matched control group. Further, a 2014 meta-analysis found that the length of training sessions had no significant effect on outcomes of WM training among older adults Karback [40]. These studies support the idea that it may be possible to improve cognitive functioning using relatively brief interventions.

However, cognitive training programmes are very controversial as transfer effects have not been observed in all studies, leading some to question whether it can ever be truly effective [41-43]. The legal trouble of the commercial brain training programme 'Lumosity' has been widely reported. The developer's claims about the efficacy of the popular programme were judged to be unfounded and a large fine imposed for breaching advertising standards [44]. Further, scientific studies have often failed to find transfer effects. Redick et al. [45] used an n-back task to train WM in a sample of young adults and compared them to both an active and passive control group. While improvement on the trained task was observed, there was no transfer to untrained simple and complex span tasks which engage WM. Thompson et al. [46] found similar results in another group of young adults also using the n-back paradigm. Studies have also shown no transfer effects in older adults. Lange \& Süß [47] used an adaptive training programme to administer 12 hours of training over 6 weeks. No transfer to closely related complex span WM tasks was seen, in contrast to previous studies.

There is concern that methodological issues in study design are causing the effects of WM training to be overstated. It is common for sample sizes to be quite small in this type of research and this may have a problematic effect on statistical power Moreau [48] Underpowered designs increase the likelihood that an important experimental effect will not be detected or, conversely, that a result will erroneously be identified as significant Bogg [49]. Various statistical and measurement procedures are also cited as problematic Tidwell [50]. In a very large review Smith et al. (2016) propose some standards that brain training studies should meet in order to be considered best practice and to increase comparability across studies. These include justifying the training time used, randomising participant allocation, and using an active control group. Studies employing these design characteristics are better equipped to make inferences about the outcomes of brain training interventions.

\section{RehaCom}

RehaCom is a cognitive rehabilitation package developed in the early 1990s Hasomed [51] Developed in order to restore cognitive abilities in people who have suffered an acquired brain injury, RehaCom has shown efficacy in increasing the mental capacities of those who have suffered stroke and traumatic brain injuries [44,52]. It has also been shown to have a positive effect in those with schizophrenia d'Amato et al. [53], multiple sclerosis Fink et al. [54], and memory recovery after temporal lobe epilepsy surgery Helmstaedter et al. [55]. RehaCom uses an adaptive training method to target and improve cognitive functions. The programme includes several modules which target selective attention, divided attention and vigilance, as well as the verbal, visual and spatial aspects of WM Hasomed [51].

\section{Current Study}

The present study sought to explore the effectiveness of the RehaCom cognitive rehabilitation programme in training WM and attention in a healthy sample. To the author's knowledge, no other study has used Rehacom with this type of group previously. By studying the program in a healthy population, conclusions can be drawn about which tasks have a greater influence on specific cognitive functions, which might aid in investigating the same tasks in individuals with brain damage.

Training took place over three weeks and comprised nine 30 minute sessions; improvement on the training tasks was monitored. A selection of pre-and post-tests was used to examine any near-transfer of training to untrained memory and attention tasks. A measure of general cognitive functioning was also used to assess far transfer. Due to the prevalence of depression and its impact on cognitive functions, levels of depressive symptoms were measured also. In carrying out this study, the researchers aimed to evaluate RehaCom in a healthy population while also adding to the existing literature regarding $\mathrm{WM}$ and attention training.

\section{Methods \\ Participants}

A total of 57 participants (25 males and 32 females), 31 in the experimental group and 26 in the active control group, took part in this experiment; participants were matched on age, level of premorbid functioning and levels of anxiety and depression. Exclusion criteria consisted of a diagnosis of degenerative nervous system, psychiatric or mental disorder and aphasia, as well as illiteracy, motor and vision problems and a history of substance abuse and learning disability. Inclusion criteria consisted of normal to corrected vision and hearing and healthy cognitive capabilities. Participants consisted of University of Edinburgh students and were contacted through e-mail or poster; they were informed that the current study aims at measuring levels of attention following cognitive training over a period of three weeks.

\section{Design}

This research study employed a longitudinal experimental design assessing improvement of attention and working memory following computerised cognitive training (RehaCom). 
Participants were divided into two groups and were randomly allocated to: an experimental group receiving computerised cognitive training and an active control group playing Solitaire over the period of three weeks. Table 1 shows a timetable layout of the procedure for each group. Both groups received the same neuropsychological tests. The independent variable (IV) is group allocation, while the dependent variable (DV) is outcome performance on post-training assessment measures.

Table 1: Timetable layout for each group.

\begin{tabular}{|c|c|c|c|}
\hline & $\begin{array}{c}\text { Experimental } \\
\text { Group } \\
\text { (RehaCom) }\end{array}$ & $\begin{array}{c}\text { Active control } \\
\text { group(Solitaire) }\end{array}$ & $\begin{array}{c}\text { Amount of } \\
\text { time required } \\
\text { for each } \\
\text { session }\end{array}$ \\
\hline T1 assessment & W1 & W1 & 90 minutes \\
\hline Session 1 & W1 & W1 & 30 minutes \\
\hline Session 2 & W1 & W1 & 30 minutes \\
\hline Session 3 & W1 & W1 & 30 minutes \\
\hline Session 4 & W2 & W2 & 30 minutes \\
\hline Session 5 & W2 & W2 & 30 minutes \\
\hline Session 6 & W2 & W2 & 30 minutes \\
\hline Session 7 & W3 & W3 & 30 minutes \\
\hline Session 8 & W3 & W3 & 30 minutes \\
\hline Session 9 & W3 & W3 & 30 minutes \\
\hline T2 assessment & W3 & W3 & 90 minutes \\
\hline
\end{tabular}

Note: $\mathrm{T} 1=$ Time $1 ; \mathrm{T} 2=$ Time $2 ; \mathrm{W} 1=$ Week $1 ; \mathrm{W} 2=$ Week $2 ; \mathrm{W} 3=$ Week 3; T1 took place typically 1-2 days before testing started; T2 took place typically 1-2 days after testing ended.

\section{Measurements and materials}

A battery of neuropsychological tests was administered preand post-training (T1 assessment and T2 assessment). These measures were chosen due to the fact that they match RehaCom training tasks and are adequate in testing of improvement in both attention and memory. The measures used at T1 and T2 assessment were as follows:

I. Test of Premorbid Functioning (TOPF-UK) (Wechsler, 2011): A measure that provides an estimation of premorbid intellectual and memory ability through the use of 70 words with atypical grapheme and phoneme pronunciation. The efficacy and reliability of the test has been verified in determining premorbid level of functioning in healthy individuals ( $r>9$ ) Dykiert [56].

II. Repeatable Battery for the Assessment of Neuropsychological Status, A and B (RBANS) (Randolph, 1998): Measure which tests negative and positive cognitive progress over numerous domains, such as attention, memory and language. It is highly valid and reliable in assessing general neuropsychological abilities $(\alpha=.8)$ Cheng et al. [57]. Neuropsychological capacity is measured through immediate recall tests (List Learning, Story Memory), delayed recall (List Recall, Story Recall, and Figure Recall), recognition memory (List Recognition), visuospatial ability
(Figure 1), language (Semantic Fluency, Picture Naming), speed of processing (Coding) and attention (Digit Span Forwards).

III. Hospital Anxiety and Depression Scale (HADS) Zigmond [58]: Self-assessment screening tool used to detect levels of depression and anxiety. The questionnaire has been validated and is reliable $(\alpha=.77)$ in measuring both anxiety and depression in healthy adults Bjelland [59].

IV. Test of Everyday Attention, A and B (TEA) Robertson [60]: Assesses numerous types of attention, including selective attention, sustained attention, divided attention and attentional switching. It includes subtests such as Map Search (selective attention), Elevator Counting and Lottery (sustained attention), Elevator Counting with Distraction (auditory selective attention), Visual Elevator and Auditory Elevator with Reversal (attentional switching) and Telephone Search Dual Task (divided attention). The test is valid and reliable in measuring attention across a healthy population $(\mathrm{r}=.59-.86)$ Ward [61].

V. Wechsler Memory Scale IV (WMS IV) - Symbol Span Subtest Wechsler [62]: A measure of visual working memory in which participants must memorize a set of symbols in the order that they saw them. This test provides a reliable $(\mathrm{r}=$ .93 ) and valid measure of visual working memory capacity Wechsler [63].

VI. Wechsler Adult Intelligence Scale IV (WAIS IV) Arithmetic, Digit Span Forward, Backward and Sequencing Subtests Wechsler [64]: Measures of working memory. In the arithmetic subtest, participants must solve a series of arithmetic problems within a limited time. In the digit span subtest, participants must immediately recall numbers either the same way as presented (i.e. forward), the reverse of how they were presented (i.e. backward), or organised in order form lowest to highest (sequencing). From these subtests, an overall Working Memory Index score will be calculated. These measures have good reliability ( $\alpha=.7-.8$ ) and validity Wechsler [65].

\section{Training task (experimental group)}

RehaCom Hasomed [51]: computerized software which aims to train healthy and patient populations in numerous cognitive domains (e.g. attention, concentration, memory). In the current study, three attention and three working memory subsets were used:

a) Divided Attention: performing numerous tasks while driving a car, such as turning left or right, slowing down or speeding up

b) Attention \& Concentration: finding a matching picture to the one presented on the right of the screen

c) Vigilance: selecting faulty objects on a production line 
d) Working Memory: memorizing and sorting playing cards in accordance with different criteria of colour, number and sequence (forward/backward)

e) Verbal Memory: reading a story and recalling details when tested immediately afterward

f) Topological Memory: memorizing the location of an array of pictures; these pictures are then hidden and the participant must recall the location of each item in turn 6 .

\section{Control task (active control group).}

a) Solitaire Game: a card game played by one person with at least one 52-card pack, in which cards are dealt in a specific pattern. The goal is to arrange all cards in a specific order. To the extent of the researchers' knowledge, Solitaire has not been found to improve attentional function, and was therefore suitable as a control task.

\section{Procedure}

Table 2: Test administration at $\mathrm{T} 1$ and $\mathrm{T} 2$.

\begin{tabular}{|c|c|}
\hline T1 assessment & T2 assessment \\
\hline HADS TOPF-UK & HADS \\
\hline RBANS A/B & RBANS A/B \\
\hline TEA A/B & TEA A/B \\
\hline $\begin{array}{c}\text { WMS IV (Symbol Span } \\
\text { subtest) }\end{array}$ & WMS IV (Symbol subtest) \\
\hline $\begin{array}{c}\text { WAIS IV (Arithmetic, Digit } \\
\text { Span Forward, Backward } \\
\text { and Sequencing Subtests) }\end{array}$ & $\begin{array}{c}\text { WAIS IV (Arithmetic, Span Forward, } \\
\text { Backward and Sequencing Subtests) }\end{array}$ \\
\hline
\end{tabular}

Note: RBANS $A / B=$ Repeatable Battery for the Assessment of Neuropsychological Function Version A/B; TEAA/B= Test of Everyday Attention Version A/B; HADS = Hospital Anxiety and Depression Scale, TOPF-UK = Test of Premorbid Functioning, WMS-IV = Wechsler Memory Scale $4^{\text {th }}$ Edn, WAIS $-I V=$ Wechsler Adult Intelligence Scale $4^{\text {th }}$ Edn.

All participants were approached by e-mail or poster and were first provided with an information sheet offering an overview of the study and its demands and were encouraged to ask questions. Neuropsychological tests were administered twice, firstly at T1 (pre-training) and again at T2 (post-training). Table 2 includes a layout of test administration at both $\mathrm{T} 1$ and T2. The order of presentation of the alternate forms of the tests was counterbalanced in order to minimise any confounding effects. Participants were given the option to be tested in two separate sessions if they became tired at any point during the procedure.

In the experimental group, 9 sessions of RehaCom, the computerised cognitive training program, were administered between the two time points, over the duration of 3 weeks. During the 9 sessions, participants were trained in attention and working memory for 30 minutes (15 minutes in attention and 15 minutes in working memory), 3 times a week in the presence of the researcher in a laboratory. In the control group, participants were given instructions to play Solitaire for 30 minutes, 3 times a week for 3 weeks. Participants in this group were given a document that comprised instructions and a calendar in order to note completion of each Solitaire session, as they did not need to come to the laboratory in order to complete Solitaire tasks, due to the fact that they were trusted to complete it on their own.

\section{Statistical Analysis}

Descriptive statistics were calculated for all subjects. Differences in age, level of premorbid functioning, and levels of anxiety and depression were investigated using independent samples T-tests. A MANCOVA with levels of anxiety and depression as covariates was run in order to observe differences between the experimental group and the active control group at T2. Lastly, a mixed ANOVA (with time-points 1 and 2 as withinsubjects variables and experimental and active control group as between-subjects variables) was run for each dependent variable (total score of RBANS, the 8 subtests of the TEA, and the subtests within the WMS IV and WAIS IV) in order to observe whether the experimental group improved in attention more than the active control group as a result of cognitive training, and if so, to what extent.

\section{Ethical Considerations}

The research study was ethically approved by the University of Edinburgh School of Philosophy, Psychology and Language Studies Ethical Research Committee on the third of March, 2016 (Reference number: 108-1516/2).

\section{Results}

Table 3: Demographic statistics for all study participants.

\begin{tabular}{|c|c|c|}
\hline Variables & $\begin{array}{c}\text { Experimental group } \\
\text { (RehaCom) }(\mathbf{N = 3 1 )}\end{array}$ & $\begin{array}{c}\text { Active control group } \\
\text { (Solitaire) }(\mathbf{N = 2 6})\end{array}$ \\
\hline Agea (years) & & \\
\hline Mean & 31.55 & 31.56 \\
\hline S.D. & 13.48 & 13.63 \\
\hline Range & $20-71$ & $21-60$ \\
\hline Men \% (N) & $52 \%(16)$ & $33 \%(9)$ \\
\hline Women \% (N) & $48 \%(15)$ & $67 \%(17)$ \\
\hline Education & & $7 \%(2)$ \\
\hline High School \% (N) & $0 \%(0)$ & $30 \%(8)$ \\
\hline University \% (N) & $23 \%(7)$ & $63 \%(16)$ \\
\hline Graduate \% (N) & $77 \%(24)$ & \\
\hline TOPFa & & 112.52 \\
\hline Mean & 112.78 & 8.10 \\
\hline S.D. & 6.74 & \\
\hline
\end{tabular}

Note: SD: Standard Deviation; TOPF: Test of Premorbid Functioning; a, $p>0.05$.

All analyses were conducted with an alpha level of .05. Unless otherwise noted, all analyses were conducted on the 57 subjects who completed the study (Table 3) for demographic characteristics of the participants). Data analysis for all 
participants was completed using z-scores calculated for the 8 TEA subtests, Working Memory Index, Symbol and Digit Spans and Arithmetic Subtest, and an RBANS composite score.

\section{Baseline Comparisons}

There were no significant differences found in age, $\mathrm{t}(56)=$ $-0.002, p=0.998$, between the experimental group $(M=31.55$, $\mathrm{SD}=13.48)$ and the active control group $(\mathrm{M}=31.56, \mathrm{SD}=13.63)$. Level of premorbid functioning, $\mathrm{t}(56)=0.944, \mathrm{p}=0.349$, was also found to be matched in the experimental group $(\mathrm{M}=0.91$, $\mathrm{SD}=0.43$ ) and the active control group ( $\mathrm{M}=0.79, \mathrm{SD}=0.57)$, as measured by an independent samples t-test. At T1 assessment, no significant differences were found in level of anxiety, $t$ (56) $=0.758, \mathrm{p}=0.451$, between the experimental group $(\mathrm{M}=6.26$, $\mathrm{SD}=3.38)$ and the active control group $(\mathrm{M}=5.59, \mathrm{SD}=3.28)$. Likewise, there were no significant differences in level of depression, $t(56)=-0.763, p=0.448$, between the experimental group $(\mathrm{M}=2.77, \mathrm{SD}=2.17)$ and the active control group $(\mathrm{M}=$

MANCOVA analysis at T2 assessment

Table 4: Time 2 assessment results - MANCOVA.

\begin{tabular}{|c|c|c|c|}
\hline & Experimental group (RehaCom) $(N=31)$ & Active control group (Solitaire) $(N=26)$ & Significance value (p) \\
\hline \multicolumn{4}{|l|}{ RBANS $^{\mathrm{a}}$} \\
\hline Mean & 113.77 & 113.28 & 0.99 \\
\hline SD & 15.31 & 12.07 & \\
\hline \multicolumn{4}{|l|}{ TEA $1^{\text {a }}$} \\
\hline Mean & -0.39 & 0.61 & 0.14 \\
\hline SD & 0.81 & 3.18 & \\
\hline \multicolumn{4}{|l|}{ TEA $2^{\mathrm{a}}$} \\
\hline Mean & -0.87 & -0.26 & 0.32 \\
\hline SD & 0.85 & 2.68 & \\
\hline \multicolumn{4}{|l|}{ TEA $3^{\mathrm{a}}$} \\
\hline Mean & 0.51 & 1.18 & 0.29 \\
\hline SD. & 0.64 & 3.09 & \\
\hline \multicolumn{4}{|l|}{ TEA $4^{\mathrm{a}}$} \\
\hline Mean & -0.34 & 0.36 & 0.41 \\
\hline SD & 1.68 & 3.69 & \\
\hline \multicolumn{4}{|l|}{ TEA $5^{\text {a }}$} \\
\hline Mean & 0.45 & 1.40 & 0.23 \\
\hline SD & 1.09 & 3.74 & \\
\hline \multicolumn{4}{|l|}{ TEA $6^{\mathrm{a}}$} \\
\hline Mean & 0.65 & 0.89 & 0.30 \\
\hline SD & 1.45 & 3.53 & \\
\hline \multicolumn{4}{|l|}{ TEA $7^{\mathrm{a}}$} \\
\hline Mean & -0.25 & 0.65 & 0.24 \\
\hline SD & 1.45 & 3.43 & \\
\hline \multicolumn{4}{|l|}{ TEA $8^{\mathrm{a}}$} \\
\hline Mean & -0.70 & -0.15 & 0.39 \\
\hline
\end{tabular}

\section{$3.33, \mathrm{SD}=3.35)$}

At T2 assessment, there were no significant differences found on level of anxiety, $t(55)=-0.31, p=0.76$, between the experimental group $(M=5.77, S D=4.28)$ and the active control group $(M=6.15, S D=5.03)$. Similarly, no significant differences were found on level of depression, $t(54)=0.02, p=0.99$, between the experimental group $(\mathrm{M}=3.74, \mathrm{SD}=5.77)$ and the active control group $(\mathrm{M}=3.72, \mathrm{SD}=3.14)$.

\section{Progress on Training Tasks}

To examine performance on the training tasks, the highest level achieved during each session was recorded for each task. These scores were then converted into units of standard deviation, in order to have all task scores on the same scale. The score from the first session was then subtracted from each of the other 8 sessions. These score progressions can be seen in Figure 1. An average improvement of 4.39 standard deviations was seen across the three tasks. 


\section{Psychology and Behavioral Science International Journal}

\begin{tabular}{|c|c|c|c|}
\hline SD & 1.32 & 3.02 & \\
\hline $\begin{array}{c}\text { WM } \\
\text { Indexa }\end{array}$ & & 5.44 & 0.33 \\
\hline Mean & 0.98 & 23.67 & \\
\hline SD & 1.06 & & \\
\hline $\begin{array}{c}\text { Symbol } \\
\text { Spana }\end{array}$ & & 1.72 & 0.13 \\
\hline Mean & 0.69 & 3.32 & \\
\hline SD & 1.12 & & \\
\hline
\end{tabular}

Note: $a, p>0.05$; RBANS = Repeatable Battery for the Assessment of Neuropsychological Function; TEA $1=$ Map Search; TEA 2 = Map Search; TEA 3 = Elevator Counting with Distraction; TEA 4 = Visual Elevator; TEA 5 = Elevator Counting with Reversal; TEA 6 = Telephone Search; TEA 7 = Telephone Search while Counting; TEA 8 = Lottery; WM Index = Working Memory Index.

Table 5: Time 2 assessment results - main effects.

\begin{tabular}{|c|c|c|c|c|c|}
\hline & $\begin{array}{l}\text { Degrees } \\
\text { of } \\
\text { freedom }\end{array}$ & $\begin{array}{c}\mathrm{f} \\
\text { value }\end{array}$ & $\begin{array}{c}\text { Significance } \\
\text { value }(p)\end{array}$ & $\begin{array}{c}\text { Partial } \\
\text { Eta } \\
\text { Squared } \\
\left(\eta p^{2}\right)\end{array}$ & $\begin{array}{c}\text { Error - } \\
\text { degrees } \\
\text { of } \\
\text { freedom }\end{array}$ \\
\hline RBANS $^{a}$ & 1 & 0.04 & 0.99 & 0.00 & 52 \\
\hline TEA $1^{\text {a }}$ & 1 & 2.29 & 0.14 & 0.04 & 52 \\
\hline TEA $2^{\mathrm{a}}$ & 1 & 1.00 & 0.32 & 0.02 & 52 \\
\hline TEA $3^{\mathrm{a}}$ & 1 & 1.16 & 0.29 & 0.02 & 52 \\
\hline TEA $4^{\mathrm{a}}$ & 1 & 0.69 & 0.41 & 0.01 & 52 \\
\hline TEA $5^{a}$ & 1 & 1.45 & 0.23 & 0.03 & 52 \\
\hline TEA $6^{\mathrm{a}}$ & 1 & 1.08 & 0.31 & 0.02 & 52 \\
\hline TEA $7^{\mathrm{a}}$ & 1 & 1.43 & 0.24 & 0.03 & 52 \\
\hline TEA $8^{\mathrm{a}}$ & 1 & 0.72 & 0.39 & 0.01 & 52 \\
\hline $\begin{array}{l}\text { WM } \\
\text { Indexa }\end{array}$ & 1 & 0.96 & 0.33 & 0.02 & 52 \\
\hline $\begin{array}{c}\text { Symbol } \\
\text { Spana }\end{array}$ & 1 & 2.37 & 0.13 & 0.04 & 52 \\
\hline
\end{tabular}

Note: $a, p>0.05 ;$ RBANS $=$ Repeatable Battery for the Assessment of Neuropsychological Function; TEA 1 = Map Search; TEA 2 = Map Search; TEA 3 = Elevator Counting with Distraction; TEA 4 = Visual Elevator; TEA 5 = Elevator Counting with Reversal; TEA 6 = Telephone Search; TEA 7 = Telephone Search while Counting; TEA 8 = Lottery; WM Index = Working Memory Index.

A multivariate analysis of covariance (MANCOVA) was employed in order to test the hypothesis that the experimental group would obtain higher scores than the active control group on post-training assessment scores, with anxiety and depression test scores as covariates in order to observe whether they influence scores in any way. It was found that after controlling for the two covariates, the main effect of group was non-significant: Pillai's Trace: $\mathrm{V}=0.13, \mathrm{f}(13,40)=0.45, \mathrm{p}=0.94, \eta \mathrm{p} 2=0.127$ (Table 4) for significance of individual tests). The main effect of group was found to be non-significant for each of the thirteen variables analysed, namely RBANS, working memory index, symbol and digit spans, arithmetic subtest and the 8 subtests of the TEA: Map Search 1 and 2, Elevator Counting with Distraction, Visual Elevator, Elevator Counting with Reversal, Telephone Search, Telephone Search while Counting and Lottery (Table 5).

\section{Mixed ANOVA analysis at T1 and T2 assessment}

A mixed analysis of variance (ANOVA) was employed in order to test the hypothesis that the experimental group would improve to a higher extent across the assessments at both time-points as compared with the active control group. All 13 dependent variables were analysed, with time-points 1 and 2 as within-subjects variables and experimental and active control group as between-subjects variables.

i. RBANS: The main effect for time was non-significant, $\mathrm{f}$ $(1,55)=3.22, p=0.08, \eta p^{2}=0.06$. There was a non-significant interaction between the time-point of the assessment and the group placement, $\mathrm{f}(1,55)=0.12, \mathrm{p}=0.73, \eta \mathrm{p}^{2}=0.00$. Group placement was found to be non-significant, $f(1,55)=$ $0.01, p=0.91, \eta p^{2}=0.00$. The results show that there was no improvement over time in either group.

ii. Map search 1 (TEA 1): The main effect for time was found to be significant, $f(1,55)=4.37, p=0.04, \eta p^{2}=0.07$. The interaction between time-point of assessment and group placement was found to be significant, $f(1,55)=3.96$, $\mathrm{p}=0.05, \eta \mathrm{p}^{2}=0.06$. Group placement was found to be nonsignificant, $f(1,55)=3.16, p=0.08, \eta p^{2}=0.05$.

As the interaction between assessment time and group placement was found to be significant, a paired-samples T-test was conducted in order to observe which group improved to a higher extent over time. No significant differences were found between the experimental group $(\mathrm{M}=-0.35, \mathrm{SD}=1.00)$ and the active control group $(\mathrm{M}=$ $-0.41, \mathrm{SD}=0.68)$ at time-point 1 assessment, $\mathrm{t}(25)=0.25$, $\mathrm{p}=0.80$. However, a near significance difference was found between the experimental group $(\mathrm{M}=-0.45, \mathrm{SD}=0.83)$ and the active control group $(\mathrm{M}=0.93, \mathrm{SD}=3.40)$ at time-point 2 assessment, $\mathrm{t}(24)=-2.00, \mathrm{p}=0.06$. Results showed that the active control group tended to improve to a higher extent than the experimental group, albeit not significantly.

iii. Map search 2 (TEA 2): The main effect of time was found to be significant, $f(1,55)=4.15, p=0.04, \eta p^{2}=0.07$. However, the interaction between time and group placement was found to be non-significant, $f(1,55)=1.99, p=0.16$, 
$\eta p 2=0.04$. This indicates that both groups improved across the two assessments, although there was no significant difference in their interaction. Moreover, the effect of group placement was found to be non-significant, $f(1,55)=1.37, p$ $=0.25, \eta p^{2}=0.02$.

iv. Elevator counting with distraction (TEA 3): The main effect of time was found to be significant, $f(1,55)=3.92$, $\mathrm{p}=0.05, \eta \mathrm{p}^{2}=0.07$, while the interaction between time and group placement was found to be non-significant, $f(1$, $55)=3.32, p=0.07, \eta p^{2}=0.06$. Therefore, improvement was observed in both groups on this task, however with no differentiation between groups. Group placement was found to have no significant effect on the results, $f(1,55)=1.43$, p $=0.24, \eta p 2=0.03$.

v. Visual elevator (TEA 4): A similar pattern of results was found within this task: time main effect was found to be significant, $f(1,55)=5.11, p=0.03, \eta p^{2}=0.09$, while the interaction between time and group placement was nonsignificant, $f(1,55)=2.65, p=0.11, \eta p^{2}=0.05$, showing that both groups significantly improved across time. The main effect of group placement was found to be non-significant, $f$ $(1,55)=1.00, \mathrm{p}=0.32, \eta p^{2}=0.02$.

vi. Elevator counting with reversal (TEA 5): The main effect of time was found to be highly significant, $f(1,55)=$ 5.27, $\mathrm{p}=0.03, \eta \mathrm{p}^{2}=0.09$, while the interaction between time and condition was found to be non-significant, $f(1,55)=$ $1.61, p=0.21, \eta p^{2}=0.03$. The main effect of group placement was found to be non-significant, $f(1,55)=.82, p=0.09, \eta p^{2}$ $=0.05$.

vii. Telephone search (TEA 6): The main effect of time on results within this task was found to be highly significant, $f$ $(1,55)=5.52, p=0.02, \eta p^{2}=0.09$. The interaction between time and group placement, $\mathrm{f}(1,55)=2.89, \mathrm{p}=0.09, \eta \mathrm{p}^{2}=$ 0.05 and the effect of group placement, $f(1,55)=1.56, p=$ $0.22, \eta p^{2}=0.03$, were found to be non-significant.

viii. Telephone search while counting (TEA 7): The main effect of both time of assessment, $\mathrm{f}(1,55)=2.78, \mathrm{p}=$ $0.10, \eta p^{2}=0.05$, and interaction between time and group placement, $f(1,55)=0.27, p=0.61, \eta p^{2}=0.01$, were found to be non-significant. However, group placement was found to be highly significant, $f(1,55)=6.92, p=0.01, \eta p^{2}=0.11$.

ix. Lottery (TEA 8): The main effect of time on this variable was found to be highly significant, $f(1,55)=18.97, p=0.00$, $\eta p^{2}=0.27$, while the interaction between time and group placement was found to be non-significant, $f(1,55)=0.45, p$ $=0.51, \eta p^{2}=0.01$. Lastly, the main effect of group placement was non-significant, $f(1,55)=0.08, p=0.78, \eta p^{2}=0.00$.

x. WM index: The main effect for time was non-significant, $f(1,54)=1.41, p=0.24, \eta p^{2}=0.03$. Likewise, there was a nonsignificant interaction between time-point of assessment and group placement, $f(1,54)=1.02, p=0.32, \eta p^{2}=0.02$. Group placement was also found to be non-significant, $\mathrm{f}$ (1, 54) $=1.19, \mathrm{p}=0.28, \eta \mathrm{p}^{2}=0.02$.

xi. Symbol span: The main effect for both time of assessment, $\mathrm{f}(1,54)=2.86, \mathrm{p}=0.09, \eta \mathrm{p}^{2}=0.05$, and interaction between time and group placement, $f(1,54)=$ 1.11, $p=0.29, \eta p^{2}=0.02$, were found to be non-significant. Likewise, the main effect of group placement was found to be non-significant, $f(1,54)=3.15, p=0.08, \eta p=0.06$.

\section{Discussion}

The present study is the first to examine the effects of RehaCom cognitive rehabilitation software on cognitive functioning in a healthy sample. The effects of three weeks of computerised brain training on near transfer measures of WM capacity and attention, and a far transfer measure of general cognitive functioning, were investigated. Pre-and post-scores on these measures were compared between a training and an active control group. Further, the effects of depressive symptoms on performance were also examined.

With regard to the computerised training modules, an improvement was observed in performance on the training tasks in the training group. All participants improved on all tasks across the nine training sessions. This finding is consistent with previous studies [66-68] which have observed positive training effects. As this effect is very commonly reproduced in training studies, it can be stated with some confidence that training improves performance on the trained tasks designed to target specific cognitive constructs Oberauer [69].

Regarding the transfer of this training to other measures of attention and working memory, no significant effect was found in this study. A trend was observed for the Map Search element of the TEA, but it did not reach significance. These results are in line with previous studies in which an improvement on the trained task has not translated into improvement on other measures of WM or attention. In their meta-analysis, Melby-Lervåg [70] highlighted the elusive nature of significant and lasting transfer effects following brain training. Variability in demographics or procedures across studies makes it difficult to be certain about the findings of such analyses. Nonetheless, it is possible that cognitive training may not produce the sizeable improvements in functioning it promises Redick [71]. Seçer [72] found that a computerised intervention designed to train divided attention in healthy adults, produced no significant transfer to related measures of attention and memory.

Using a similar training schedule as the present study, the authors cite this short intervention time as a possible issue, which is discussed below in relation to our findings here. A recent study by Lindeløv et al. [73], found that both healthy and acquired brain injury people improved significantly on trained tasks but this did not translate into better performance on closely-related untrained tasks. The authors suggest that such 
findings raise the possibility that brain training interventions may be most effective when they are closely modelled on the real-world behaviour which one wishes to improve, rather than attempting to tap into higher-level cognitive constructs.

While near transfer sometimes fails to reproduce in training studies, far transfer is even more elusive and many studies have failed to find an effect broader measures of cognition $[45,46,66,74,75]$. This type of transfer requires much greater generalisation of training to the constructs underlying different aspects of cognitive performance Lange Süß [47]. Given that no significant near transfer effects were found in the current study, it is not surprising that there was no far transfer effect. Borella et al. [37] reported that there was no far transfer after training, even when near transfer was noted on a Backwards WM Span Task. Training induced change in cognitive abilities is hypothesised to happen hierarchically, beginning with near transfer to underlying cognitive abilities and then extending to other functions, therefore when near transfer is not present an improvement in general cognitive ability cannot be expected $[66,76]$. The training intervention must successfully enhance basic WM and attention abilities before it can generalise to performance on a measure which encompasses immediate and delayed memory, and processing speed, as the RBANS does.

There was no effect of depressive symptoms on training outcomes in the current sample. Overall, self-reported levels of depression were quite low in the current sample (mean $=3.44$, out of a possible 21) across both sessions. Bjelland et al. [59] suggest a score of 8 out of 21 as the minimum cut-off for possible depression. In general, the deleterious effect of depression on cognitive functioning is reported in people who have high or clinical levels of depressive symptoms $[77,78]$. For this reason, attention and WM abilities may not have been affected in the current sample.

\section{Strengths and Implications}

The current study extends beyond the existing literature on cognitive training by evaluating the brain-training capabilities of RehaCom rehabilitation software with healthy people and it presents a number of strengths. The most important is the novelty of the present study, in terms of a comparison between RehaCom and a simple game (Solitaire) in improving attentional and WM skills in the healthy, adult brain. Although it has been investigated in clinical studies observing a variety of neurological and psychiatric disorders [52,79], no previous studies have investigated RehaCom's effects on the healthy adult brain. As computer programmes developed for clinical use, such as Cogmed, became more widespread, their effects on nonclinical populations have also been investigated Shipstead et al. [76]. As RehaCom is relatively new to clinical practice in the UK, it is important to assess its potential with a range of populations.

The current study therefore shows that attentional and working memory tasks in RehaCom do not significantly improve cognitive functions in a healthy population. This preliminary result might inform clinical studies investigating RehaCom's efficacy in improving cognitive functions; in other words, if improvement as a result of RehaCom is not shown in a healthy population, further clinical studies might be needed in order to show that patients with brain damage truly improve their cognitive functions solely as a result of RehaCom tasks, and not due to other confounding variables.

Moreover, to the extent of the researchers' knowledge, no other study has used the frequency and duration of training employed in the current study. In cognitive training research, finding the optimum training schedule is very important Penner et al. [36]. A balance must be struck between the proposed outcome and the time commitment of a training regime Moreau Conway [80]. Hence the shorter training time was chosen for this investigation in order to fit in with a busy modern life and also with the average consultation time available in a clinical setting. Furthermore, the present study led to the conclusion that RehaCom is not significantly efficacious in improving attention and WM in a healthy population, at least not at the frequency and type of modules used in this study. However, an improvement on the training tasks was observed across training sessions. This might indicate that perhaps the issues in the current study were choice of pre- and post-assessment, frequency or amount of time allowed for training. This preliminary finding adds to the research regarding RehaComs's efficacy and although the initial hypothesis that cognitive functions will improve as a result of RehaCom was rejected, there are a number of implications and reflections of the current study which could be helpful in future research, especially within the clinical field.

Studying the healthy brain is key in understanding cognitive training across clinical populations. By gaining insight into mechanisms of the healthy brain, deficits found in clinical populations may be more easily targeted and training may be optimized to patients' needs [81,82]. For instance, Bartels [83] investigated practice effects in neuropsychological tests on cognition in healthy individuals. They stated that in order for neuropsychological tests to be optimised in terms of design, administration and interpretation, they must first be tested on the healthy brain in order to observe performance in healthy conditions. Similarly, Onken [82] argued that investigation of the healthy brain is an efficient comparative condition in gaining an understanding of both clinical cognitive processes and behaviour change. Cognitive rehabilitation in clinical populations is extremely important given the wide-ranging potential impact of neuropsychological impairments, particularly in terms of social and occupational reintegration Slomine [84]. As such, the present study's results aid in informing the effects of computerised cognitive training in the healthy population and how this could transfer to studies investigating clinical populations, which in turn may lead to an optimisation of cognitive rehabilitation programmes. 


\section{Limitations}

This study aimed to use a relatively short training time that would reduce fatigue and could be more easily integrated into a participant's daily life. As RehaCom has not been used with a healthy population previously, it is possible that the chosen training time was not sufficient to produce an effect which is observable across many measures of WM. With regard to other cognitive training packages, more intensive training schedules have been used commonly in the literature - e.g. 30-45 minute sessions over several weeks $[69,85,86]$. However, as discussed earlier, short interventions have also been used successfully in previous studies [37-39]. In a very large-scale study, Owen et al. [87] used a short training schedule - on average participants completed twenty-four 10 minute sessions. The authors noted that there was no correlation between the numbers of sessions completed and transfer outcomes. In contrast to this, a metaanalysis by Schwaighofer [88] suggested that training dose and session duration did have a significant effect on training results. In the current study, all participants completed all nine training sessions so this type of correlation cannot be investigated for the data. Therefore, the possibility that a longer training time may have produced significant transfer effects cannot be excluded.

Moreover, participants in the active control group might not have completed all nine sessions of Solitaire. A log sheet was provided to all participants in order to remind them to play and record each session. However, researchers cannot know for certain that all nine sessions were successfully completed, as they were carried out in their absence. In any brain training study using healthy participants, it is important to discuss a possible ceiling effect at baseline and its impact on results. Ball et al. [89] attempted to investigate whether cognitive training would improve mental and daily functions in healthy, older adults. Their results indicate that although a number of participants significantly improved their cognitive abilities as a result of training, there was an observed ceiling effect at the time of the first testing session, which might explain the lack of significant improvement and development for most others. That is, the ceiling effect signified that the tests administered were too simple for participants, leading to obtainment of high scores and masking a possible improvement as a result of cognitive training. In the present study, data was collected from healthy individuals with intact cognitive abilities who obtained high scores in all assessments. Therefore, perhaps the selected sample was biased in terms of educational level. An implication drawn from the current study would be to observe the effects of RehaCom on attentional skills in healthy individuals with more variation in level of cognitive function. Perhaps if a more widespread sample in terms of education and intelligence would be selected, a ceiling effect would not occur at baseline, and the effects of RehaCom would be registered without the interference of this confounding variable [90-95].

\section{Conclusion}

In conclusion, this study is important as it is the first to investigate the brain-training capabilities of RehaCom computerised rehabilitation software with a non-clinical sample. The results from the present study could not fully support the initial hypothesis that RehaCom would be efficient in improving cognitive functions in the healthy, adult brain as, though an improvement was observed on training tasks, there was no significant transfer to related WM and attention tasks. This might be the result of numerous external factors, such as chosen frequency and training modules and demographic characteristics. Further investigation is needed in order to better understand the impact of RehaCom as a cognitive training program within the healthy population as well as its efficacy, both short- and long-term. It is recommended that future research might investigate RehaCom's usefulness in a population such as healthy older adults who are at risk of cognitive decline or across more clinical populations.

\section{References}

1. Fisher H (2000) Lust attraction, attachment: biology and evolution of the three primary emotion systems for mating, reproduction, and parenting. J Sex Educ Ther 28(1): 96-104.

2. Schiefenhövel $W$ (2009) Romantic love. A human universal and possible honest signal. Hum Ontog 3(2): 39-50.

3. Stewart-Williams S, Thomas AG (2013) The ape that thought it was a peacock: Does evolutionary psychology exaggerate human sex differences? PsycholInq 24(3): 137-168.

4. Lovejoy CO (1981) The origin of man. Science 211(4480): 341-350.

5. Bateman A (1948) Intrasexual selection. Heredity 2: 349-368.

6. Trivers RL (1972) Parental investment and sexual selection. In: Stich S (edn) Nat Sel Soc Theory Sel Pap. Robert Trivers, Oxford University Press pp: 65-110.

7. Hrdy SB (1999) The Woman That Never Evolved. Harvard University Press, Oxford, England.

8. Dunbar R (2010) Deacon's dilemma: the problem of pair-bonding in human evolution. Proceeding Br Acad 158: 154-175.

9. Conroy-Beam D, Goetz CD, Buss DM (2015) Why do humans form longterm mateships? An evolutionary game-theoretic model. Adv Exp Soc Psychol 51(1): 1-39.

10. Buss DM, Schmitt DP (1993) Sexual strategies theory: An evolutionary perspective on human mating. Psychol Rev 100(2): 204-232.

11. Symons D (1980) Evolution of Human Sexuality.

12. Thornhill R, Gangestad SW (2008) The Evolutionary Biology of Human Female Sexuality. Archives of Sexual Behavior 38(6): 1067-1069.

13. Goetz AT, Shackelford TK (2009) Sexual conflict in humans: evolutionary consequences of asymmetric parental investment and paternity uncertainty. Anim Biol 59(4): 449-456.

14. Benshoof L, Thornhill R (1979) The evolution of monogamy and the loss of estrous in humans. J Soc Biol Struct 2(2): 95-106.

15. Marlowe F (2000) Paternal investment and the human mating system. Behav Processes 51(1): 45-61. 
16. Strassmann BI, Kurapati NT, Hug BF (2012) Religion as a means to assure paternity. Proc Natl Acad Sci 109(25): 9781-9785.

17. Hite S (1981) El Informe Hite sobre la Sexualidad Masculina. Plaza, Janés, SA Editores.

18. Small MF (1992) The evolution of female sexuality and mate selection in humans. Hum Nat 3(2): 133-156.

19. Dixson AF (2009) Sexual Selection and the Human Mating System. Oxford University Press.

20. Burchell JL, Ward J (2011) Sex drive, attachment style, relationship status and previous infidelity as predictors of sex differences in romantic jealousy. Pers Individ Dif 51: 657-661.

21. Morell V (1998) A new look at monogamy. Science (80- ) 281(5385): 1982-1983.

22. Anderson KG (2006) How well does paternity confidence match actual paternity? Evidence from worldwide nonpaternity rates. Curr Anthropol 47(3): 513-520.

23. Goetz AT, Shackelford TK, Romero GA, et al. (2008) Punishment, proprietariness, and paternity: Men's violence against women from an evolutionary perspective. Aggress Violent Behav 13: 481-489.

24. Larmuseau MHD, Vanoverbeke J, Van Geystelen A, et al. (2013) Low historical rates of cuckoldry in a Western European human population traced by Y-chromosome and genealogical data. Proc R Soc B Biol Sci 280(1772): 20132400.

25. Lovejoy CO (2009) Reexamining human origins in light of Ardipithecus ramidus. Science 326: 74 .

26. Pedersen WC, Putcha-Bhagavatula A, Miller LC (2011) Are men and women really that different? Examining some of sexual strategies theory (SST)'s key assumptions about sex-distinct mating mechanisms. Sex Roles 64: 629-643.
27. Buss DM (1989) Sex differences in human mate preferences: evolutionary hypotheses tested in 37 cultures. Behav Brain Sci 12: 1-49.

28. Buss DM, Barnes M (1986) Preferences in human mate selection. J Pers Soc Psychol 50(3): 559-570.

29. Buss DM (1988) The evolution of human intrasexual competition: Tactics of mate attraction. J PersSocPsychol 54(4): 616-628.

30. Buss DM, Shackelford TK, Kirkpatrick LA, Larsen RJ (2001) A half century of mate preferences: The cultural evolution of values. Psychology 63(2): 491-503.

31. Hyde JS (2005) The gender similarities hypothesis. Am Psychol 60(6): 581-592.

32. Petersen JL, Hyde JS (2011) Gender differences in sexual attitudes and behaviors: A review of meta-analytic results and large datasets. J Sex Res 48(2): 149-165.

33. Hyde JS (2014) Gender similarities and differences. Annu Rev Psychol 65: 373-398.

34. Hite S (1977) El Informe Hite. Plaza, Janés, SA Editores.

35. Alonso DL (2014) Biología de la Homosexualidad. Síntesis, Madrid, Spain.

36. Alonso DL, Ortiz-Rodríguez IM (2017) Offspring mortality was a determinant factor in the evolution of paternal investment in humans: An evolutionary game approach. J Theor Biol 419: 44-51.

37. Lloyd EA (2005) The Case of the Female Orgasm. Harvard University Press, USA.

38. Marlowe FW (2003) A critical period for provisioning by Hadza men. Implications for pair bonding. Evol Hum Behav 24(3): 217-229.

\section{Your next submission with Juniper Publishers} will reach you the below assets

- Quality Editorial service

- Swift Peer Review

- Reprints availability

- E-prints Service

- Manuscript Podcast for convenient understanding

- Global attainment for your research

- Manuscript accessibility in different formats

( Pdf, E-pub, Full Text, Audio)

- Unceasing customer service

Track the below URL for one-step submission https://juniperpublishers.com/online-submission.php 